\title{
Experiences and Opinions Related to End-of-Life Discussion: From Oncologists' and Resident Physicians' Perspectives
}

\author{
Su-Jin Koh, MD, $P h D^{1}$ \\ Shinmi Kim, RN, PhD² \\ JinShil Kim, RN, $P h D^{3}$ \\ Bhumsuk Keam, MD, PhD ${ }^{4}$ \\ Dae Seog Heo, MD, PhD \\ Kyung Hee Lee, MD, PhD ${ }^{5}$ \\ Bong-Seog Kim, MD, PhD ${ }^{6}$ \\ Jee Hyun Kim, MD, PhD \\ Hye Jung Chang, $\mathrm{MD}^{8}$ \\ Sun Kyung Baek, MD, PhD ${ }^{9}$
}

\begin{abstract}
${ }^{1}$ Department of Hematology and Oncology, Ulsan University Hospital, Ulsan University College of Medicine, Ulsan, ${ }^{2}$ Department of Nursing, Changwon National University, Changwon, ${ }^{3}$ College of Nursing, Gachon University, Incheon, ${ }^{4}$ Department of Internal Medicine, Seoul National University Hospital, Seoul, ${ }^{5}$ Department of

Hemato-Oncology, Yeungnam University, Daegu, ${ }^{6}$ Department of Hemato-Oncology, Veterans Health Service Medical Center, Seoul, ${ }^{7}$ Department of Internal Medicine, Seoul National University Bundang Hospital, Seongnam, ${ }^{8}$ Department of Internal Medicine, Kyung Hee University Hospital at Gangdong, Seoul, ${ }^{9}$ Department of Internal Medicine, Kyung Hee University Medical Center, Seoul, Korea
\end{abstract}

\section{Purpose}

The aims of this study were to explore how oncologists and resident physicians practice end-of-life (EOL) discussions and to solicit their opinions on EOL discussions as a means to improve the quality of EOL care.

\section{Materials and Methods}

A survey questionnaire was developed to explore the experiences and opinions about EOL discussions among oncologists and residents. Descriptive statistics, the t test, and the chisquare test were performed for the analyses.

\section{Results}

A total of 147 oncologists and 229 residents participated in this study. The study respondents reported diverse definitions of "terminal state," and most respondents tried to disclose the patient's condition to the patient and/or family members. Both groups were involved in EOL care discussions, with a rather low satisfaction level (57.82/100). The best timing to initiate discussion was considered when metastasis or disease recurrence occurred or when withdrawal of chemotherapy was anticipated. Furthermore, the study respondents suggested that patients and their family members should be included in the EOL discussion. Medical, legal, and ethical knowledge and communication difficulties along with practical issues were revealed as barriers and facilitators for EOL discussion.

\section{Conclusion}

This study explored various perspectives of oncologists and resident physicians for EOL discussion. Since the Life-Sustaining-Treatment Decision-Making Act will be implemented shortly in Korea, now is the time for oncologists and residents to prepare themselves by acquiring legal knowledge and communication skills. To achieve this, education, training, and clinical tools for healthcare professionals are required.

\section{Key words}

Advance care planning, Communication, Oncologists, Resident physician

Correspondence: Shinmi Kim, RN, PhD Department of Nursing, Changwon National University, 20 Changwondaehak-ro, Uichang-gu, Changwon 51140, Korea Tel: 82-55-213-3571

Fax: 82-55-213-3579

E-mail: skim@changwon.ac.kr 


\section{Introduction}

Cancer is the most prevalent cause of death in Korea, despite recent advances in anti-cancer therapy. Currently, death is usually processed within the medical care delivery system, while the distinction between life and death has been obscured by advanced medical technology [1]. Thus, discussions and decisions on medical care, including hospice and palliative care (HPC) during the end-of-life (EOL) period, have become more important [2,3]. Dying is an extremely private experience that varies from person to person [4]. Therefore, it is important to consider each patient's personal values and wishes for EOL care. To advocate the patients' wishes and to allow self-determination for EOL care, the use of the advance directives (AD) and physician's order of lifesustaining-treatment (POLST) have been recommended in western countries, and these are included in the Life-Sustaining-Treatment Decision-making Act for dying and hospice/ palliative care patients (LST Decision Act), which will be enforced shortly in Korea. The LST Decision Act specifies the physician's explanation about EOL treatment options, including LST and hospice care, and about POLST in the context of advance care planning (ACP). During the ACP process, patients who are near their EOL, including terminal cancer patients, can get the opportunity to discuss their wishes for future healthcare decisions with all stakeholders, including physicians, family members, and/or others [5]. The product of this process is either AD or POLST, and the key factor for making decisions considering the patient's best interest is communication among the stakeholders during this type of discussion [6].

Given that EOL discussions will become more important in Korea along with the implementation of the LST Decision Act, studies to identify clinical situations and/or strategies to facilitate this type of discussion are needed, as these are currently lacking. Therefore, this study was performed to explore the issues or problems hindering EOL discussions and to suggest strategies for better EOL discussions. To this end, this study aimed to (1) identify the patterns and barriers that oncologists and resident physicians have experienced in EOL discussions in current clinical circumstances and (2) solicit their opinions about better EOL discussions, particularly in terms of the facilitators needed in such discussions.

\section{Materials and Methods}

Oncologists and resident physicians who treated cancer patients during the study period were invited to participate in this survey. The survey was performed from June 2013 to January 2014 using a questionnaire. The study questionnaire was developed by the authors to explore the oncologists' and residents' experiences and opinions on EOL discussion. To develop the questionnaire, query items were generated by the authors, and the content validity of the generated items was subsequently verified through an expert review process. The draft questionnaires were polished to obtain a final version of the questionnaire after a pilot test with a sample of five oncologists and five residents. The final questionnaires were distributed to the eligible subjects by two methods: directly administered at the 2013 annual symposium of the Korean Cancer Association for oncologists and mailed to oncologists who had agreed to distribute the questionnaires to the resident physicians in their affiliated institutions.

The characteristics of each group of respondents are presented using descriptive statistics. Differences in EOL discussion experiences and opinions for better discussion between the oncologists and residents were examined using the $t$ test or chi-square test, as appropriate.

\section{Results}

\section{Subject characteristics}

A total of 379 participants agreed to participate in this study. Of these, three respondents were excluded due to incomplete responses. Hence, the final sample consisted of 376 physicians, including 147 oncologists and 229 residents. The demographic characteristics of the respondents are presented in Table 1. As expected, the oncologist group was older, contained a higher proportion of married individuals, and showed a higher education level. More oncologists were also religious, while the affiliations were similar between the two groups.

\section{Experience in EOL discussion}

Approximately two-thirds of the oncologists (64.4\%) and residents $(61.7 \%)$ referred to "terminal stage" as a life expectancy of either less than 6 months or less than 2-3 months. In both groups, almost all respondents tried to disclose the bad news to the patients and / or their family members (Table 2). The two groups showed a significant difference regarding the timing to initiate EOL discussion $(p<0.001)$. The oncologists reported that they usually began EOL discussion when chemotherapy was expected to be discontinued, while the residents most frequently did so when the life expectancy was less than 6 months. Both groups 
Table 1. General characteristics of respondents

\begin{tabular}{|c|c|c|c|}
\hline Variable & Total $(n=376)$ & Oncologist $(n=147)$ & Resident (n=229) \\
\hline \multicolumn{4}{|l|}{ Sex } \\
\hline Male & $225(59.84)$ & 78 (53.1) & $147(64.19)$ \\
\hline Female & $151(40.16)$ & $69(46.9)$ & $82(35.81)$ \\
\hline Age (yr) & $33.43 \pm 7.13$ & $39.26 \pm 7.72$ & $29.68 \pm 2.99$ \\
\hline \multicolumn{4}{|l|}{ Marital state } \\
\hline Single & $179(47.61)$ & $38(25.85)$ & 141 (61.57) \\
\hline Married & $195(51.86)$ & 107 (72.79) & $88(38.43)$ \\
\hline Widowed & $1(0.27)$ & $1(0.68)$ & 0 \\
\hline Divorced & $1(0.27)$ & $1(0.68)$ & 0 \\
\hline \multicolumn{4}{|l|}{ Education (degree) } \\
\hline Bachelor & $226(60.11)$ & $30(20.41)$ & $196(85.59)$ \\
\hline Master & $87(23.14)$ & $56(38.10)$ & 31 (13.54) \\
\hline Doctoral & $63(16.76)$ & $61(41.50)$ & $2(0.87)$ \\
\hline \multicolumn{4}{|l|}{ Religion } \\
\hline None & $179(47.61)$ & $50(34.01)$ & $129(56.33)$ \\
\hline Protestant & $108(28.82)$ & $55(37.41)$ & $53(23.14)$ \\
\hline Catholic & 60 (15.96) & $33(22.45)$ & 27 (11.79) \\
\hline Buddhist & $29(7.71)$ & $9(6.12)$ & $20(8.73)$ \\
\hline \multicolumn{4}{|l|}{ Affiliation } \\
\hline GH & $281(74.73)$ & 108 (73.47) & $173(75.55)$ \\
\hline Intermediate GH & $88(23.40)$ & $34(23.13)$ & $54(23.58)$ \\
\hline Clinic & $7(1.86)$ & $5(3.40)$ & $2(0.87)$ \\
\hline
\end{tabular}

Values are presented as number (\%) or mean \pm standard deviation. GH, general hospital.

reported that oncologists were the ones who usually initiated EOL discussions in their clinical practice. Both groups reported that the patients and family members were the major discussion participants. However, a difference in the discussion participants was observed between the two groups as well, with a significantly larger proportion of residents discussing the EOL care with the family members only, in the absence of the patients. In terms of the discussion topics, disease trajectory issues, including the progress and prognosis of disease $(92.82 \%)$, and the possibility of recovery $(82.71 \%)$ were the most frequent topics. As for EOL care options, cardiopulmonary resuscitation (CPR; 77.13\%), HPC $(73.40 \%)$, LST $(71.54 \%)$, and the place of EOL care $(58.51 \%)$ were the four most common subjects discussed. Relatively low proportions of respondents reported that they discussed the benefits and burden of chemotherapy $(37.23 \%)$ and any alternative treatments $(23.14 \%)$. Interestingly, proxy appointments were also discussed by a small proportion of respondents $(22.07 \%)$. The difficulty in life expectancy estimation was explored as the major barrier for residents $(61.14 \%)$, whereas family members' reluctance to include the patient in the discussion was the most common barrier $(55.78 \%$ ) for oncologists (Table 2).
The average number of cases per month that involved EOL discussions was 6.24, and the number of patients that were transferred to HPC significantly differed between the groups, with more HPC transfers occurring in the oncologist group than in the resident group. Overall, the level of satisfaction regarding the EOL discussion practiced in each respondent's institution was reported to be rather low (57.82 of 100).

\section{Opinions for better EOL discussion process}

Discontinuation of chemotherapy and exacerbation of disease such as metastasis or recurrence of disease were suggested as the two most significant indications to begin EOL discussion by both oncologists and residents (Table 3). The majority of respondents $(83.33 \%)$ considered oncologists as the most appropriate persons to initiate the EOL discussion. Regardless of the groups, hospice care specialists (41.10\%) were suggested as the best expert for conducting ongoing EOL discussions. However, there were significant differences in the opinion about the other qualified experts for ongoing EOL discussions between the two groups; more oncologists $(35.71 \%)$ considered palliative coordinators as adequate per- 
Table 2. Experience in end-of-life discussion

\begin{tabular}{|c|c|c|c|c|}
\hline EOL discussion & $\begin{array}{c}\text { Total } \\
(n=367)\end{array}$ & $\begin{array}{l}\text { Oncologist } \\
(n=147)\end{array}$ & $\begin{array}{l}\text { Resident } \\
(\mathrm{n}=229)\end{array}$ & p-value \\
\hline \multicolumn{5}{|l|}{ Definition of terminal state $\left.{ }^{a}\right)$} \\
\hline Life expectancy 6 months or less & $127(34.05)$ & $50(34.25)$ & $77(33.92)$ & 0.563 \\
\hline Life expectancy 2-3 months & $107(28.69)$ & $44(30.14)$ & $63(27.75)$ & \\
\hline Deterioration of condition & $77(20.64)$ & $24(16.43)$ & $53(23.35)$ & \\
\hline Discontinuation of chemotherapy & $49(13.34)$ & $23(15.75)$ & $26(11.45)$ & \\
\hline Impending death & $2(0.54)$ & 0 & $2(0.88)$ & \\
\hline Others & $11(2.95)$ & $5(3.42)$ & $6(2.64)$ & \\
\hline \multicolumn{5}{|l|}{ Timing to initiate discussion ${ }^{a}$} \\
\hline Life expectancy 2-3 months or less & $75(20.16)$ & $31(21.68)$ & $44(19.21)$ & $<0.001$ \\
\hline When chemotherapy is expected to be discontinued & $74(19.89)$ & $36(25.17)$ & $38(16.59)$ & \\
\hline Life expectancy 6 months or less & $73(19.62)$ & $21(14.69)$ & $52(22.70)$ & \\
\hline Upon chemotherapy discontinuation & $63(16.94)$ & $34(23.78)$ & $29(12.66)$ & \\
\hline Upon metastasis or recurrence & $48(12.90)$ & $14(9.79)$ & $34(14.85)$ & \\
\hline Impending death & $21(5.65)$ & $1(0.70)$ & $20(8.73)$ & \\
\hline Upon cancer diagnosis & $15(4.03)$ & $3(2.10)$ & $12(5.24)$ & \\
\hline Others & $3(0.81)$ & $3(2.10)$ & 0 & \\
\hline \multicolumn{5}{|l|}{ Notification bad news } \\
\hline Always notify & $247(65.69)$ & $103(70.07)$ & $144(62.88)$ & 0.327 \\
\hline Notify as much as possible & $128(34.04)$ & $44(29.93)$ & $84(36.68)$ & \\
\hline Not notify as possible & $1(0.27)$ & 0 & $1(0.44)$ & \\
\hline Others & $10(2.77)$ & $2(1.45)$ & $8(3.59)$ & \\
\hline \multicolumn{5}{|l|}{ Discuss with $^{\text {a) }}$} \\
\hline Patients and family members & $234(62.73)$ & $109(75.17)$ & $125(54.82)$ & $<0.001$ \\
\hline Family members & $133(35.66)$ & $32(22.07)$ & $101(44.30)$ & \\
\hline Patients & $6(1.61)$ & $4(2.76)$ & $2(0.88)$ & \\
\hline \multicolumn{5}{|l|}{ Discussion subjects $^{\text {b) }}$} \\
\hline Prognosis & $349(92.82)$ & $135(91.84)$ & $213(93.01)$ & \\
\hline Cardiopulmonary resuscitation & $291(77.13)$ & $99(67.35)$ & $191(83.41)$ & \\
\hline Hospice / Palliative care & $276(73.40)$ & $113(76.87)$ & $164(71.62)$ & \\
\hline Life-sustaining treatments & $269(71.54)$ & $95(64.63)$ & $173(59.83)$ & \\
\hline Place of EOL care & $220(58.51)$ & $85(57.82)$ & $134(58.52)$ & \\
\hline Benefits and burden of chemotherapy & $140(37.23)$ & $49(33.33)$ & $89(38.86)$ & \\
\hline Alternative treatments & $87(23.14)$ & $49(33.33)$ & $38(16.59)$ & \\
\hline Proxy appointment & $83(22.07)$ & $30(20.41)$ & $53(23.14)$ & \\
\hline \multicolumn{5}{|l|}{ Hospice palliative care transfera) } \\
\hline $1-2$ times $/ \mathrm{mo}$ & $155(42.12)$ & $43(30.50)$ & $112(49.34)$ & $<0.001$ \\
\hline 3-5 times / mo & $110(29.89)$ & $35(24.82)$ & $75(33.04)$ & \\
\hline None & 45 (12.22) & $24(17.02)$ & $21(9.25)$ & \\
\hline 6-10 times $/ \mathrm{mo}$ & $30(8.15)$ & $18(12.77)$ & $12(5.29)$ & \\
\hline$\geq 10$ times / mo & $28(7.61)$ & $21(14.89)$ & $7(3.08)$ & \\
\hline No. of EOL discussion per month & $6.24 \pm 9.10$ & $7.60 \pm 11.96$ & $5.44 \pm 6.65$ & 0.031 \\
\hline Level of satisfaction about EOL discussion & $57.82 \pm 17.39$ & $57.85 \pm 17.58$ & $57.69 \pm 17.35$ & 0.935 \\
\hline
\end{tabular}

Values are presented as number $(\%)$ or mean \pm standard deviation. ${ }^{a}$ Missing data excluded from analysis, ${ }^{\text {b)} M u l t i p l e ~ r e s p o n s e . ~}$

sonnel to continue the discussion, compared to in the resident group (21.78\%), whereas more residents $(35.56 \%)$ than oncologists $(21.43 \%)$ believed that oncologists were the most appropriate personnel for ongoing discussions. Most study respondents reported that both the patients and their family members should be included in the discussion together. Furthermore, CPR (95.74\%), mechanical ventilation $(89.63 \%)$, and hemodialysis $(64.36 \%)$ were the treatment options dis- 
Table 3. Opinions for better end-of-life discussion

\begin{tabular}{|c|c|c|c|c|}
\hline EOL discussion & $\begin{array}{c}\text { Total } \\
(n=367)\end{array}$ & $\begin{array}{c}\text { Oncologist } \\
(n=147)\end{array}$ & $\begin{array}{l}\text { Resident } \\
(n=229)\end{array}$ & p-value \\
\hline \multicolumn{5}{|l|}{ Timing to initiate discussion $\left.{ }^{a}\right)$} \\
\hline When chemotherapy discontinuation is expected & $112(30.03)$ & $48(32.88)$ & $64(29.96)$ & 0.117 \\
\hline Upon metastasis or recurrence & $108(28.95)$ & $52(35.62)$ & $56(24.67)$ & \\
\hline Upon diagnosis of cancer & $73(19.57)$ & $22(15.07)$ & $51(22.47)$ & \\
\hline Upon chemotherapy discontinuation & $56(15.01)$ & $17(11.64)$ & $39(17.18)$ & \\
\hline When one is healthy & $16(4.29)$ & $4(2.74)$ & $12(5.29)$ & \\
\hline Impending death & $4(1.07)$ & $1(0.68)$ & $3(1.32)$ & \\
\hline Others & $4(1.07)$ & $2(1.37)$ & $2(0.88)$ & \\
\hline \multicolumn{5}{|l|}{ Discussion initiated by ${ }^{a}$} \\
\hline Oncologists & $305(83.33)$ & $121(84.61)$ & $184(82.51)$ & 0.772 \\
\hline Hospice care specialist & $44(12.02)$ & $14(9.79)$ & $30(13.45)$ & \\
\hline Palliative care coordinator & $11(3.01)$ & $5(3.50)$ & $6(2.69)$ & \\
\hline Others & $6(0.44)$ & $3(2.10)$ & $3(1.35)$ & \\
\hline \multicolumn{5}{|l|}{ Ongoing discussion by ${ }^{a}$} \\
\hline Hospice care specialist & $150(41.10)$ & $57(40.71)$ & $93(41.33)$ & 0.035 \\
\hline Oncologists & $110(30.14)$ & $30(21.43)$ & $80(35.56)$ & \\
\hline Palliative care coordinator & $99(27.12)$ & $50(35.71)$ & $49(21.78)$ & \\
\hline Chaplaincy & $2(0.55)$ & $1(0.71)$ & $1(0.44)$ & \\
\hline Others & $4(1.10)$ & $2(1.43)$ & $2(1.89)$ & \\
\hline \multicolumn{5}{|l|}{ Discuss with ${ }^{\text {a) }}$} \\
\hline Patients and families & $318(85.24)$ & $127(87.00)$ & $191(84.14)$ & 0.781 \\
\hline Patients & $31(8.31)$ & $11(7.53)$ & $20(8.81)$ & \\
\hline Families & $23(6.17)$ & $8(5.48)$ & $15(6.61)$ & \\
\hline Others & $1(0.27)$ & 0 & $1(0.44)$ & \\
\hline \multicolumn{5}{|l|}{ Treatment options included in discussion ${ }^{\text {b) }}$} \\
\hline Cardiopulmonary resuscitation & $360(95.74)$ & $137(93.20)$ & $223(97.38)$ & \\
\hline Mechanical ventilation & $337(89.63)$ & $131(89.12)$ & $206(89.96)$ & \\
\hline Hemodialysis & $242(64.36)$ & $101(68.71)$ & $141(61.57)$ & \\
\hline Artificial nutrition/Hydration & $135(35.90)$ & $72(49.00)$ & $63(27.51)$ & \\
\hline Blood transfusion & $91(24.20)$ & $43(29.25)$ & $48(20.96)$ & \\
\hline Antibiotics & $63(16.76)$ & $31(21.09)$ & $32(13.97)$ & \\
\hline \multicolumn{5}{|l|}{ Factors considered for LST decision makinga) } \\
\hline Patient's wishes or values & $194(54.19)$ & $73(52.52)$ & $121(55.25)$ & 0.743 \\
\hline Family's opinions & $79(22.07)$ & $28(20.14)$ & $51(23.29)$ & \\
\hline Physician's opinions & $65(18.16)$ & $29(20.86)$ & $36(16.44)$ & \\
\hline Opinions of proxy & $17(4.75)$ & $7(5.04)$ & $10(4.57)$ & \\
\hline Others & $3(0.84)$ & $2(1.44)$ & $1(0.46)$ & \\
\hline
\end{tabular}

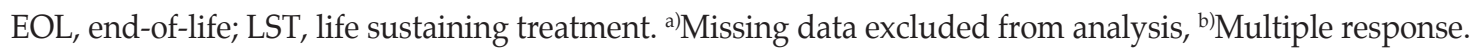

cussed for EOL care by most respondents. The respondents reported the patients' wishes or values toward EOL care as the most important factor to be considered in the decision of LST (Table 3).

\section{Barriers and facilitators}

The most prevalently recognized barriers for EOL discussion were the family's reluctance to include a patient in the discussion $(55.78 \%)$ and prognostication difficulty $(61.14 \%)$ in the oncologist and resident groups, respectively. Family members' request for continuation of treatment $(42.29 \%)$, conflict among family members (39.89\%), concerns about disappointment or hopelessness of the patient $(38.30 \%)$, time constraints $(22.07 \%)$, and fear of death or feelings of guilt $(21.54 \%)$ were also reported as barriers across all respondents. In a minor proportion, practical issues, including legal and communicational issues, were mentioned as well (Table 4). 
Table 4. Barriers and facilitators of end-of-life discussion

\begin{tabular}{|c|c|c|c|}
\hline Category & Total $(n=376)$ & Oncologist $(\mathrm{n}=147)$ & Resident $(\mathrm{n}=\mathbf{2 2 9})$ \\
\hline \multicolumn{4}{|l|}{ Barriers $^{a)}$} \\
\hline Prognostication difficulty & $213(56.65)$ & $71(48.30)$ & $140(61.14)$ \\
\hline Family's reluctance to include a patient in discussion & $175(46.54)$ & $82(55.78)$ & $92(40.17)$ \\
\hline Family's request for continuation of treatment & $159(42.29)$ & $56(38.10)$ & $103(44.98)$ \\
\hline Conflict among family members & $150(39.89)$ & $47(31.97)$ & $101(44.10)$ \\
\hline Concerns about disappointment or hopelessness & $144(38.30)$ & $63(42.86)$ & $81(35.37)$ \\
\hline Lack of time & $83(22.07)$ & $46(31.29)$ & $37(16.16)$ \\
\hline Fear of death or guilty feeling & $81(21.54)$ & $27(18.37)$ & $54(23.58)$ \\
\hline Probable legal issues & $34(9.04)$ & $7(4.76)$ & $27(11.79)$ \\
\hline Lacking in communication skills & $26(6.91)$ & $10(6.80)$ & $15(6.55)$ \\
\hline \multicolumn{4}{|l|}{ Facilitators ${ }^{\text {a) }}$} \\
\hline Knowledge about prognostication & $254(67.55)$ & $84(59.18)$ & $170(74.24)$ \\
\hline $\begin{array}{l}\text { Understanding of patient and family member's } \\
\text { socio-psychological aspects }\end{array}$ & $212(56.38)$ & $86(58.50)$ & $126(55.02)$ \\
\hline Knowledge of treatments and hospice care & $133(35.37)$ & $50(34.01)$ & $83(36.24)$ \\
\hline Experiences of treatments and hospice care & $117(31.12)$ & $54(36.73)$ & $61(26.64)$ \\
\hline Communication skills & $111(29.52)$ & $53(36.05)$ & $58(25.33)$ \\
\hline Constitution of palliative care team & $91(24.20)$ & $42(28.57)$ & $49(21.40)$ \\
\hline Conflict resolution skills & $72(19.15)$ & $21(14.29)$ & $51(22.27)$ \\
\hline Knowledge about legal and ethical issues & $57(15.16)$ & $17(11.56)$ & $40(17.47)$ \\
\hline Payment for counselling services & $56(14.89)$ & $27(18.37)$ & $29(12.66)$ \\
\hline Coping skills for psychological distress & $33(8.78)$ & $11(7.48)$ & $22(9.61)$ \\
\hline
\end{tabular}

Values are presented as number (\%). ${ }^{\text {a) } M u l t i p l e ~ r e s p o n s e . ~}$

Both groups considered knowledge or understanding about prognostication $(67.54 \%)$ and the patients' and their family members' socio-psychosocial status $(56.38 \%)$ as the major facilitating factors for EOL discussions (Table 4). Knowledge (35.37\%) and experience $(31.12 \%)$ in terms of the treatment options and hospice care, communication skills $(29.52 \%)$, palliative care team $(24.20 \%)$, conflict resolution skills $(19.15 \%)$, knowledge about legal and ethical issues $(15.16 \%)$, payment for counseling services $(14.89 \%)$, and coping skills for psychological distress $(8.78 \%)$ were also claimed as facilitating factors (Table 4 ).

\section{Discussion}

This study aimed to investigate the clinical practice of EOL discussions, especially for terminal cancer patients, and the professional opinions on how to ensure better EOL discussions and what the major barriers and facilitators were conceived to be.

The oncologists and resident physicians reported various definitions of "terminal state" in the present study, suggesting that the terminal state is diversely interpreted by healthcare professionals, similar to what was reported in a previous study [7]. In more than half of the study respondents, the terminal state was regarded as a life expectancy of less than 6 months or less than 2-3 months by both the oncologists and residents. These results seem relevant considering the facts that the terminal state is defined as a life expectancy of 6 months or less in the U.S. Medicare policy [8] and that the LST Decision Act defines the terminal state as the state in which impending death might occur within a few months. However, in a previous study, concerns about the definition of "terminal state" based on a specific period of life expectancy were raised, and the necessity of taking the whole context into consideration was emphasized [9]. The American Cancer Society also defined the terminal state more broadly, without referring to life expectancy [10]. In addition, uncertainty about the illness trajectory has been recognized as an important barrier for discussing EOL care [11]. Therefore, a more comprehensive definition of terminal state would be desirable, and a disease-based definition has recently been proposed in the enforcement regulation of the LST Decision Act. 
The diverse definitions could influence the communication between the physicians and patients, as well as among healthcare providers. According to a study on whether the same language was used for communication between healthcare professionals and the general population [12], 74.5\% of adults referred to "advanced breast cancer with lung metastasis" as a "terminal" illness, which was different from the medical opinion. This finding suggests that efforts should be made to narrow the gap in the understanding of the relevant terms, including "terminal state" between healthcare professionals and the general population [12], aside from establishing consensus among healthcare providers for clearer EOL discussion. In addition, the LST Decision Act distinguishes the terms "terminal state" and "dying phase" and specifies each definition respectively. Putting aside controversies regarding the statements of the Act, healthcare providers need to practice the law, and oncologists and residents need to acknowledge the lawful definitions and diagnostic criteria for the terminal state and dying phase of cancer patients.

In the present study, the oncologists and residents showed a significant difference in the timing for EOL discussion, with various times emerging. Most residents initiated EOL discussions when the life expectancy was expected to be less than 6 or 2-3 months, while the oncologists did so around the time cancer treatment was interrupted, especially when chemotherapy was expected to be discontinued. Interestingly, similar to in the oncologist group, the resident group suggested the best timing to initiate EOL discussion as when withdrawal of chemotherapy was expected and the disease state deteriorated, that is, the residents did not practice what they preached. However, explaining the gap between opinions and practice among residents is beyond the scope of this study, and efforts should be made to narrow the gap in practice in the future. Nevertheless, the diverse practices and opinions about the discussion timing in this study not only reflect how difficult it is to suggest any concrete process for EOL discussion, but also support the notion that it is important to consider the whole context in EOL discussion [13].

Furthermore, almost all respondents tried to inform the patient and / or their family members of the patient's condition. This result is quite encouraging and differs from that of a previous study in which the physicians preferred to avoid this type of communication [14]. Noteworthy, more residents (44.3\%) than oncologists $(22.7 \%)$ discussed the EOL care only with the family members. This finding has great implications in two aspects: first, it has been well recognized that patients are usually excluded from EOL discussions in Korea. Second, only patients can make decisions for their own EOL care via $\mathrm{AD}$ or POLST under the LST Decision Act. In these regards, more emphasis needs to be placed on the importance of patient participation in EOL discussions, particularly for resident physicians. On the contrary, most study respondents argued that both patients and their family members should be involved in EOL discussions. Therefore, means to support them to practice what they preach will be necessary.

From the results of the questionnaire on the clinical experience with terminal cancer patients, more oncologists than residents reported that they transferred patients to HPC, and this result was similar to that of a previous study [13]. Timely transfer to HPC has been argued to allow the patients and their family better outcomes and quality of life in a complex landscape of cancer treatment [15]. Such being the case, early palliative care referral concurrent with active treatment was recommended in a previous study [16]. Therefore, strategies to encourage timely referral to HPC, especially for resident physicians, need to be identified and practiced.

Both the oncologists and residents referred to oncologists and palliative care specialists as the most appropriate experts for EOL discussion initiation and ongoing communication, respectively. Actually, in clinical practice, cancer patients and their family members usually rely on oncologists, who order treatments and provide medical information to them. However, oncologists are generally restricted in time for such ongoing and time-consuming communication; thus, an HPC team approach might be a feasible alternative for ongoing EOL discussions. In the current clinical setting, the residents also host EOL discussions and transfer patients to HPC services, although significantly less frequently than oncologists. Therefore, education, training, and supporting systems particularly designed for resident physicians are called for.

More than half of the study respondents suggested CPR, mechanical ventilation, and hemodialysis as treatment options to be mentioned in the EOL discussion. This is similar to the results of previous studies $[7,17]$. Moreover, these three treatment options are listed as life-sustaining treatments in the LST Decision Act, along with chemotherapy. In addition, artificial nutrition/hydration, blood transfusion, and antibiotics were also suggested as EOL care options to be discussed, albeit by relatively low proportions of respondents. Different attitudes toward artificial nutrition/hydration were also noted between the oncologists and residents, with the residents considering the necessity of decision-making regarding this procedure as low. According to a previous study [7], more than $70 \%$ of patients, caregivers, and adults considered discussion of this treatment as necessary. These different perspectives among healthcare providers, patients, and caregivers may cause conflicts in the decision-making and mutual understanding. Furthermore, this option is not included in the LST Decision Act, which is different from in other countries, including in the United States. Thus, caution should be practiced while healthcare providers communicate treatment options not listed in the Act, even though they believe that those treatment options deserve to be discussed, as long as the law is valid. 
In the present study, almost all respondents tried to communicate bad news to the patient and/or family members, and revealed a rather low satisfaction level (57.82/100) regarding the current EOL discussion process. This low satisfaction level might be interrelated with the barriers and facilitators reported herein, which could be categorized into two major issues, namely knowledge (medical, legal, and ethical) and communication (skills and policies) issues. These two issues are key components of various EOL care guidelines [18-20] and require prompt attention since the LST Decision Act is expected to be increasingly practiced in the near future in Korea and since more oncologists and/or residents are expected to be involved in EOL discussions, whether they are prepared for it or not.

These two issues of knowledge and communication need to be discussed further since they are such critical aspects in EOL discussion. First, as for knowledge, prognosis estimation was both the major barrier and facilitator and was also identified as the main subject of EOL discussion in current practice. Therefore, prognostication issues need to be recognized as the most important topic in EOL discussion. Accurate prognosis estimation is especially important because it can ensure adequate EOL care decision-making, including timely HPC transfer. Accordingly, knowledge for prognostication should be considered the most important and urgent issue in preparing physicians for the EOL discussion process. Diverse prognostic models have been introduced for more accurate survival prediction, and one model for terminal cancer patients was validated in Korea, with higher effectiveness than doctors' estimation [21]. More unified and validated tools for specific illnesses are required to aid the healthcare providers in this matter.

Another aspect that requires attention is the discussion about the benefits/burdens of chemotherapy, which was found to be suboptimal in this study. The benefit/burden of each treatment is known to represent essential information for EOL discussion [18] and should not be overlooked. Accurate medical information could allow the patients and family members to make proper decisions, and issues related to the benefit/burden of treatment are also considered important, along with prognostic information. Furthermore, knowledge or experience of diverse treatments, hospice care, and legal and ethical aspects was also recognized as important aspects for better EOL discussion by the study respondents, and the design of education and training modules including these subjects would be helpful.

In this study, the family members' reluctance to include the patient in the discussion, family conflicts, psychosocial aspects such as hopelessness, and even the communication skills of the physician emerged as both barriers and facilitators. These matters are all associated with communication. The underpinning philosophy of the LST Decision Act is patient autonomy and choice, and this philosophy could be supported through the ongoing process of ACP, which is now viewed as an intrinsic component of the EOL care program [22]. The concept of ACP has become broader [22], and communication is critical for effective EOL discussion in the context of ACP [18]. Therefore, practical and case-based communication guidelines or manuals need to be developed for healthcare providers.

Furthermore, while communicating with patients and their family members, healthcare providers need to consider cultural aspect, because all human decisions are closely related to culture [23], and EOL discussions should hence be performed in a cultural context [23,24]. Thereby, EOL discussion guidelines that correspond to Korean culture are required. In this regard, a previous study [12] proposed that the decision-making dynamics surrounding the patient needs to be taken into account for proper discussion.

Interestingly, in the present study, some respondents claimed their fears of death and / or feelings of guilt as barriers, indicating that the psychological aspect of the terminal care providers also is important. In the National Comprehensive Cancer Network guidelines [21], psychosocial support for palliative care providers after they lost a patient is included. Thus, in future EOL care guidelines in Korea, psychosocial support for the care providers, during as well as after the care, should be considered.

Efforts to support self-determination, as described in the LST Decision Act, in discussing EOL care may not be always successful, considering the present study results of family members' reluctance to discuss the EOL care with their loved ones, evidence suggesting that not all patients want an active role in making the decisions [14], and that the preparation rate of $\mathrm{AD}$ in the United States is low [25]. If so, efforts should be made to facilitate EOL discussions in a larger framework and to allow healthcare professionals to flexibly cope with individual matters. In this context, the present study proposes that the EOL discussion should be concentrated on the process, rather than on documentation itself, and that $\mathrm{AD}$ or POLST should be considered as both the vehicle and product of the discussion. Accordingly, there is no doubt that EOL discussion is critical to ensure better quality of life for the last months and days of the patient. Again, it is indispensable for healthcare professionals not only to have medical expertise, but also to communicate effectively by considering the patients' and their family members' psychological needs. Thus, the importance of knowledge and communication skills is obvious and cannot be emphasized enough to facilitate EOL discussions. Education and training for each target group, such as oncologists or resident physicians, need to be developed in the two dimensions of knowledge and communication, and social marketing would also be required to improve the stakeholder engagement. 
In conclusion, this study revealed various perspectives of oncologists and resident physicians about EOL discussion in terms of the definition of terminal stage, clinical experience of EOL discussion, and opinions for better EOL discussion. The study respondents considered that knowledge of the medical, legal, and ethical aspects and communicational preparation were essential to deal with awkward situations of EOL care discussion process. The present study suggests that efforts should be made to educate and train healthcare providers who are engaged in EOL discussion, considering that the LST Decision Act will soon be implemented.

\section{Conflicts of Interest}

Conflict of interest relevant to this article was not reported.

\section{References}

1. Office of Disability, Aging and Long-Term Care Policy (DALTCP). Advance directives and advance care planning: report to Congress. Washington, DC: Office of the Assistant Secretary for Planning and Evaluation, U.S. Department of Health and Human Services; 2008.

2. Kaplan RM, Frosch DL. Decision making in medicine and health care. Annu Rev Clin Psychol. 2005;1:525-56.

3. Rogne L, McCune SL. Introduction: a matter of life and death. In: Rogne L, Lauraine S, McCune SL, editors. Advance care planning: communicating about matters of life and death. New York: Springer; 2014. p. 1-9.

4. Committee on Approaching Death: Addressing Key End of Life Issues; Institution of Medicine. Dying in America: improving quality and honoring individual preferences near the end of life. Washington, DC: National Academies Press; 2014.

5. Levi BH, Green MJ. Too soon to give up: re-examining the value of advance directives. Am J Bioeth. 2010;10:3-22.

6. Amjad H, Towle V, Fried T. Association of experience with illness and end-of-life care with advance care planning in older adults. J Am Geriatr Soc. 2014;62:1304-9.

7. Lee JK, Yun YH, An AR, Heo DS, Park BW, Cho CH, et al. The understanding of terminal cancer and its relationship with attitudes toward end-of-life care issues. Med Decis Making. 2014;34:720-30.

8. Medicare benefit policy manual. Chapter 9 . Coverage of hospice services under hospital insurance (Rev.209.) [Internet]. Baltimore, MD: Centers of Medicare and Medicaid Services; 2015 [cited 2016 Aug 20]. Available from: https://www.cms. gov/Regulations-and-Guidance/Guidance/Manuals / downloads/bp102c09.pdf.

9. Koh SJ, Kim S, Kim J. Communication for end-of-life care planning among Korean patients with terminal cancer: A contextoriented model. Palliat Support Care. 2016;14:69-76.

10. Korea Law Information Center [Internet]. Sejong: Ministry of Health and Welfare; 2016 [cited 2016 May 16]. Available from: http:// www.law.go.kr/lsSc.do?menuId=0\&subMenu=1\& query $=\% \mathrm{EC} \% 97 \% \mathrm{~B} 0 \% \mathrm{~EB} \% \mathrm{AA} \% 85 \% \mathrm{EC} \% 9 \mathrm{D} \% 98 \% \mathrm{~EB} \% \mathrm{A3} \%$ 8C\# undefined.

11. Sharp T, Moran E, Kuhn I, Barclay S. Do the elderly have a voice? Advance care planning discussion with frail and older individuals: a systematic literature review and narrative synthesis. Br J Gen Pract 2013;63:e657-68.

12. Kim SH, Shin DW, Kim SY, Yang HK, Nam E, Jho HJ, et al. Terminal versus advanced cancer: do the general population and health care professionals share a common language? Cancer Res Treat. 2016;48:759-67.

13. Keam B, Yun YH, Heo DS, Park BW, Cho CH, Kim S, et al. The attitudes of Korean cancer patients, family caregivers, oncologists, and members of the general public toward advance directives. Support Care Cancer. 2013;21:1437-44.

14. Frosch DL, Kaplan RM. Shared decision making in clinical medicine: past research and future directions. Am J Prev Med. 1999;17:285-94.

15. Rangachari D, Smith TJ. Integrating palliative care in oncology: the oncologist as a primary palliative care provider. Cancer J. 2013;19:373-8.

16. Ferrell BR, Temel JS, Temin S, Alesi ER, Balboni TA, Basch EM, et al. Integration of palliative care into standard oncology care: American Society of Clinical Oncology clinical practice guideline update. J Clin Oncol. 2017;35:96-112.

17. Kim JS, Kim S, Hong YS, Hong S. Professional opinions on advance directives in Korea. J Hosp Palliat Nurs. 2014;16: 273-81.

18. Berlinger N, Jennings B, Wolf SM. The hastings center guidelines for decisions on life-sustaining treatment and care near the end of life: revised and expanded second edition. New York: Oxford University Press; 2013.

19. Ngo-Metzger Q, August KJ, Srinivasan M, Liao S, Meyskens FL Jr. End-of-Life care: guidelines for patient-centered communication. Am Fam Physician. 2008;77:167-74.

20. National Comprehensive Cancer Network. NCCN Clinical practice guidelines in oncology (NCCN guidelines), ver. 1. Fort Washington, PA: National Comprehensive Cancer Network; 2016.

21. Kim ES, Lee JK, Kim MH, Noh HM, Jin YH. Validation of the prognosis in palliative care study predictor models in terminal cancer patients. Korean J Fam Med. 2014;35:283-94.

22. Boyd K, Mason B, Kendall M, Barclay S, Chinn D, Thomas K, et al. Advance care planning for cancer patients in primary care: a feasibility study. Br J Gen Pract. 2010;60:e449-58. 
23. Ryan J, Harrison J. Barriers to advance care planning: a sociological perspective. In: Rogne L, McCune SL, editors. Advance care planning: communication about matters of life and death. New York: Springer; 2014. p. 45-59.

24. Meisel A. End-of-life care. In: Crowley M, editor. From birth to death and bench to clinic: the Hastings Center bioethics briefing book for journalists, policymakers, and campaigns. Garrison, NY: The Hastings Center; 2008. p. 51-4.

25. Institute of Medicine. 2015 Dying in America: improving quality and honoring individual preferences near the end of life. Washington, DC: The National Academies Press; 2015. 